\title{
Redes sociais e saúde
}

\author{
J oselma C. Cordeiro, Universidade de Pernambuco ${ }^{1}$
}

\section{Reseña}

\section{Martins, P.H \& Fontes, B. (2004). Redes sociais e saúde: novas possibilidades teóricas. Recife: Editora Universitária da UFPE, 159 p.}

Este livro como um dos exemplos de uma praxis participativa na América Latina atual constitui uma das respostas à formação de uma rede de produção entre pesquisadores da sociologia e da saúde coletiva que tem como meta a elaboração de saberes complexo, teórico e prático sobre esse tipo de relação, no estado de Pernambuco, no nordeste do Brasil.

As atividades de pesquisa e de reflexões conjuntas foram realizadas, por um lado, por pesquisadores do NUCEM (Núcleo de Cidadania, Exclusão e Processos de Mudança) do Programa de Pós-Graduação em Sociologia da Universidade Federal de Pernambuco UFPE e, por outro, pelos pesquisadores do Departamento de Saúde Coletiva - NESC do Centro de Pesquisa Aggeu Magalhães - CPqAM da Fundação Oswaldo Cruz - FIOCRUZ, em torno do de um estudo sobre "Redes sociais, cidadania e problemas endêmicos" financiado pelo Ministério da Saúde - MS e pela Fundação de Pesquisa de Pernambuco - FACEPE e realizado entre 2003 e 2004.

Este trabalho se propõe a não somente ser uma fonte de reflexão teórica, mas igualmente um guia para apoiar intervenções de agentes públicos, governamentais e não-governamentais comprometidos com a construção de redes de cidadania e de associações solidárias, capazes de legitimar e garantir historicamente os esforços de mudança da cidadania que os profissionais e intelectuais da saúde, no Brasil, vêm perseguindo.

\footnotetext{
${ }^{1}$ Médica, Professora Assistente do Departamento de Medicina Social, Faculdade de Ciências Médicas, Universidade de Pernambuco. Aluna do Doutorado em Saúde Pública do NESC/CPqAM/ FIOCRUZ. Email: cordeirojc@hotmail.com. Atual estagiária de doutorado com Bolsa do Centro de Aperfeiçoamento de Pessoal de Nível Superior - CAPES do Ministério da Educação do Brasil, sob orientação do Professor Tomás Rodrigues Villasante do Departamento de Sociologia II da Universidad Complutense de Madrid.
} 
Para tanto, buscaram estimular o diálogo ou cruzar os caminhos entre a sociologia e a saúde coletiva a partir da introdução do conceito de rede social. Nesta obra os autores demonstram ter o entendimento de que o conceito de rede social, mesmo ainda em fase de sistematização teórica e metodológica, se configura como um recurso poderoso para explicar o potencial mobilizador da sociedade civil e as perspectivas políticas inovadoras que as ações solidárias geradas horizontalmente entre indivíduos e grupos sociais, no interior da sociedade civil, nas instâncias de poder dos governos municipais e locais, etc., podem oferecer para a compreensão dos desafios de construção da cidadania democrática neste mundo globalizado e instável desta contemporaneidade.

E, enfatizam que o conceito de rede social é oportuno não só por centrar o foco de análise sobre os atores sociais fixados em certas posições ou status, mas, principalmente, sobre a relação propriamente dita. Concorrendo assim, para salientar que o valor básico da ação social localiza-se não nas preferências ou interesses dos atores sociais, mas, na relação social em si mesma, ou seja, na sua morfologia, densidade, intensidade e sentido.

Ressaltam, ainda, que a teoria antiga de rede de Mauss no seu célebre Ensaio sobre a dádiva de 1924 (Mauss, 2003, Caillé, 2002, apud Martins \& Fontes, 2004:36 e 43), esclarecer a importância fundamental do simbólico para a construção da cidadania. Assim, na teoria de rede social o que se enfatiza não é o que se ganha ou se perde materialmente, mas, o que circula na vida social em favor da organização coletiva, aparecendo, às vezes, como perda, outras, como ganho, não apenas material, mas, sobretudo, simbólico.

Para os dois coordenadores a escolha dos textos recorreu aos conceitos, redes sociais e saúde, buscando responder à necessária aproximação dos saberes entre o social e a saúde a partir de dois enfoques.

Um deles no campo sociológico, revelando a importância de se compreender a saúde como fato resultante das interações humanas, produto da vida em sociedade, em oposição aos estudos sociológicos clássicos sobre saúde que eram centrados nas práticas médicas, nas relações entre médico e paciente (T. Parsons, E. Goffman apud Martins \& Fontes, 2004:09). 
Os autores se perguntaram por que a sociologia acadêmica tem mostrado, até aquele momento, um desinteresse para o campo disciplinar específico da sociologia da saúde, prestando pouca atenção às novas significações que as questões da saúde vêm trazendo para a organização da cidadania e da vida social. E, coloca que isto vem sendo revisto na medida em que áreas urbanas densamente povoadas e mal planejadas passam a se constituir em terreno fértil para a proliferação de doenças e para o aumento dos índices de mortandade com reflexos negativos sobre os mecanismos de socialização dos indivíduos e de formação da cidadania.

E, para os mesmos, a falência das instituições sociais, como vem mostrando o recrudescimento da violência e da criminalidade, também vem forçando a introduzir o sofrimento como assunto que vem penetrando, progressivamente, no domínio propriamente dos estudos sociológicos. Porém, é assumido que tal perspectiva inovadora de análise não é facilmente assimilada pelos sociólogos, devido ao fato de que a sociologia não saber lidar convenientemente com os aspectos simbólicos da vida social.

O outro enfoque, nos campos da antropologia médica e de disciplinas das ciências da saúde, como a epidemiologia, a medicina social e da saúde coletiva. Nestes, a articulação entre saúde e sociedade se faz quando se passa a questionar a definição do processo saúde-doença como fator meramente biológico. E, mais recentemente, nas últimas décadas, existe todo um esforço de se implementar mudanças paradigmáticas tanto na prática como nos estudos sobre o campo da saúde, rebatendo intrinsecamente no campo da sociologia e estimulando este diálogo.

A saúde deixou de ser entendida como ação preventiva para ser compreendida como promoção, não se referindo mais a uma determinada doença ou desordem, mas, à qualidade de vida resultante de um complexo processo condicionado por diversos fatores tais como, entre outros, alimentação, justiça social, ecossistema, renda e educação (Czeresnia, 2003: 46 apud Martins \& Fontes, 2004: 12).

Reconhece-se que o impacto da afirmação do paradigma da promoção à saúde sobre a sociologia surge, por um lado, a partir das mudanças institucionais e políticas representadas pela Atenção Básica, que privilegia a família como objeto da ação sanitária e pela Vigilância à Saúde que privilegia o território e a intersetorialização das ações, respondendo a complexidade do objeto saúde a partir da sua definição afirmativa. A criação do Sistema Único de Saúde (SUS) com a Constituição de 1988, e o surgimento de programas territorializados como o Programa de Saúde da Família 
(PSF) ou o Programa de Saúde Ambiental (PSA), representam fatos que quebram com a cultura médico-hospitalar indiferente às implicações sociais da prática médica.

Essa nova compreensão também questiona a estrutura curricular da formação dos profissionais de saúde, de modo que se incorpora novo parâmetro mais humanístico, ético e comunitário e se evita a submissão dos valores das profissões de saúde aos interesses do mercado, sendo o médico tão mais eficaz e consistente na sua profissão "quanto mais puder articular o conhecimento teórico e técnico da ciência médica aos aspectos afetivos, sociais, culturais e éticos da relação profissional-usuário (Kruse, 2001: 16-18 apud Martins \& Fontes, 2004:13).

A prioridade dada ao caráter interativo pela valorização da família ou dos aspectos simbólicos, éticos e afetivos na relação entre profissional e usuário no processo de cura e, também, a intenção de submeter às inovações tecnológicas à primazia do relacional, permitiu o florescimento de uma cultura de cuidados na saúde mais plural e humana que se revela em algumas idéias: atenção primária à saúde, interdisciplinaridade e participação popular na organização e no bem-estar social.

Perseguindo este raciocínio foi composta a primeira sessão do livro com o título: "Novos paradigmas em sociologia: as redes sociais" onde introduzem os leitores ao conhecimento dos conteúdos de três textos que buscam elucidar as questões teóricas sobre redes sociais.

O primeiro, de Paulo Henrique Martins, enfatiza a relação entre rede social e complexidade numa perspectiva sócio-histórica e, como a teoria da dádiva está profundamente imbricada na constituição desse conceito.

Para Martins enquanto as mudanças paradigmáticas não ocorrerem, o campo sociológico continuará prisioneiro das visões dualista de redes sociais, seja do estruturalismo e do individualismo, que se sabe limitadas para permitir o acesso teórico ao princípio do paradoxo. E, para ele o paradoxo é constitutivo do objeto societal.

Propõe que para avançar no resgate da noção de rede numa abordagem mais complexa e paradoxal, integrando as contradições dos olhares do todo e das partes, deve-se resgatar as contribuições de certos autores renomados do pensamento sociológico, para demonstrar que a luta pela construção de um pensamento complexo vem de longe e para tanto recorre aos autores clássicos da sociologia como: Durkenheim, Mauss e Elias (apud Martins \& Fontes, 2004:31). 
Com Emile Durkheim o autor ressalta a perda de força da dualidade clássica do pensamento entre indivíduo e sociedade em detrimento de uma abordagem pluridimensional que, sem negar a o valor do indivíduo, considera a idéia de totalidade como central na constituição da sociedade, mesmo que para ele a totalidade seja vista como distinta das partes.

Com Marcel Mauss, seguindo o desenvolvimento da escola sociológica francesa, Martins pretendeu demonstrar que o caráter prático da noção de rede apenas emerge com força total quando se incorpora a compreensão da ação social como sistema aberto a trocas de informações ambivalentes e intensas entre o todo e as partes e vice-versa.

E, é com a contribuição de Mauss, com a sistematização da teoria da dádiva, que aparece como de maior relevância o debate teórico sobre paradoxo, ou seja, da complexidade sistêmica inerente ao vínculo social, que pode explicar que o todo está na parte e a parte no todo.

Com Norbert Elias, Martins refere a grande contribuição na busca de ultrapassar o dilema indivíduo versus sociedade, introduzindo a idéia de interdependência entre um e outro, e na tentativa de superar essa dicotomia clássica propondo, explicitamente, a noção de redes de função.

O segundo texto, de Breno Fontes que, a partir da teoria do capital social, procura definir a idéia de rede a partir das experiências de associação voluntária, tendo por objetivo discutir duas questões básicas. A primeira é quais os prováveis rearranjos destas instituições provocadas pelas profundas mudanças por que tem passado as sociedades ocidentais. A segunda é sobre as possíveis relações existente entre os processos associativos e a estrutura de redes sociais na qual estão inseridos.

A partir de uma revisão da literatura Fontes realiza uma análise exploratória da relação entre mudanças na macro-estrutura social e rearranjos na estrutura das redes sociais e as implicações nos processos de mobilização coletiva, uma temática relativamente ainda pouco exploradas.

Ressalta que a questão central na agenda de pesquisa sobre o impacto das mudanças sociais nos padrões organizativos das associações voluntárias é o questionamento se as sociedades contemporâneas estariam assistindo a um processo de fragilização dessas associações e se isto estaria resultando em deterioração da solidariedade, com conseqüências sobre o nível de engajamento cívico. 
Para tanto, discute associações voluntárias comparando a realidade dos países desenvolvidos e subdesenvolvidos. Para o cenário norte-americano o autor reconhece que a tese apresentada por Putnam de que o padrão típico de cidadão daquele país estaria em declínio é polêmica, pois, inúmeros estudos têm demonstrado que o trabalho voluntário e o espírito de associativismo dos norte-americanos e o nível de engajamento cívico permanecem vigorosos ou têm aumentado.

Nas sociedades do hemisfério sul o fenômeno do associativismo também estaria em franca mudança. Para os países da América Latina estaria ocorrendo uma certa perda de entusiasmo por parte dos analistas sobre a capacidade dos movimentos sociais produzirem mudanças significativas por um lado e por outro, a produção de 70 e 80 oferecem uma visão bastante otimista dos movimentos na luta contra as desigualdades sociais.

Porém, o que modificou, segundo Fontes, foi à forma atual de organização, existe um novo padrão organizativo, com uma redefinição da prática dos atores sociais, com uma inserção pronunciada nos processos de participação em gestão pública, uma associação mais estreita desses movimentos com Ongs, estes em franca expansão, entidades religiosas, setor público para produção de serviços com a minimização de práticas antes predominantes de protesto e contestação.

Isto devido a que os atores, para garantirem sua sustentabilidade no angariamento de recursos, tem que se organizar em redes que ultrapassam as fronteiras dos espaços da comunidade territorial, associando-se com outros atores das esferas locais, nacionais ou mesmo internacional.

Para concluir, Fontes propõe que além das pesquisas sobre movimentos sociais, cidadania, exclusão social e associações voluntárias e seus impactos sobre os processos de sociabilidade que resultam em engajamento cívico, deveriam ser estimulados estudos que privilegiem a abordagem das redes sociais para a compreensão desses fenômenos com interessantes visões e muitas respostas.

O terceiro, de Jacques Godbout, sociólogo canadense e um dos sistematizadores contemporâneos do paradigma da dádiva, fazem uma aproximação original da idéia de rede com a de mercado, revendo sua crítica ao utilitarismo, procurando demonstrar que, por um lado, esta doutrina não explica em absoluto o princípio da comunidade, por outro, o utilitarismo tem o mérito de destacar uma posição central da modernidade entre produtores e usuários, repensando o mercado a partir da teoria das redes sociais, antes só pensada como aparelho. 
Neste faz uma distinção teórica pertinente entre aparelhos e redes. Para ele, os aparelhos constituem ajuntamentos de atores sociais organizados especificamente para fins de regulação externa de públicos. E, público é definido como um conjunto de indivíduos que mantêm uma relação de exterioridade com a organização. Para Godbout, diferentemente, as redes não possuem público, elas se referem aos processos de regulação que se dirigem a um conjunto de membros. Sendo, portanto, autoreguladoras não existindo a ruptura entre o dentro e o fora, ou entre indivíduos e sociedade.

Para este autor a sociedade moderna funciona a partir das redes sociais primárias (família, vizinhos), fundamentadas sobre o tempo, onde os vínculos exigem uma dimensão de obrigação coletiva mais ampla, na qual a dimensão econômica é relevante, mas está subordinada a outras dimensões como à moral numa das extremidades, e na outra sobre a rede mercantil, cujos vínculos se afirmam unicamente pela obrigação do contrato, são desligadas do tempo e alimentadas de espaços.

Para este autor, ainda, a força das sociedades capitalistas é ter a rede como princípio de funcionamento, em relação a outras formas de extensão espacial que a humanidade conheceu anteriormente, todas fundadas mais nos aparelhos, como os impérios.

O título da segunda sessão do presente livro é "Redes sociais, saúde coletiva e controle da dengue", onde foi reunido um conjunto de quatro textos diretamente voltados para as questões da saúde.

No primeiro, Lia Giraldo Augusto, médica e epidemiologista, esclarece os aspectos decisivos sobre a saúde coletiva e as novas exigências demandadas pelo paradigma da Promoção da Saúde. E, o faz apresentando os elementos atuais do debate que integram a saúde à questão ambiental, considerada condição necessária para o desenvolvimento humano.

Esta autora inicia seus argumentos inspirados na nova perspectiva para a saúde pública - a saúde coletiva, como um novo campo de saber, gerado pelos sanitaristas brasileiros, que, na luta pela democracia, nas décadas de 70 e 80, conformaram um movimento político-ideológico com orientação do ex-Partido Comunista. 
Nesta perspectiva, a Saúde Coletiva foi concebida como campo de saber e de práticas que se fazem a partir de uma visão integrada e comprometida socialmente com a vida. E, em sua evolução, ganhou corpo teórico e contribuições de diversas disciplinas, que se integram para conhecer o processo saúde-doença, em toda a sua globalidade e complexidade.

Resgata, a partir de Tabellini (2003) a lógica complexa que preside a saúde onde leva em conta os fatos da natureza, da sociedade, os valores e ideais de busca de plenitude, da superação, da beleza, do gozo, do bem-querer e da dignidade humana. E o ambiente é compreendido, também, a partir de uma visão integradora dos valores potenciais da natureza, as externalidades sociais e da complexidade do mundo. Nesta visão o ambiente deixa de ser apenas uma dimensão externa ao homem e passa para a condição de subsistema integrador das demais dimensões da vida do ser humano.

Para tanto, as relações entre saúde-ambiente é proposta por Tabellini (2003) como um modelo onde o ambiente é visto como um sistema sócio-ecológico e a causalidade incorporam a incerteza e nela estão em jogo duas lógicas, a da natureza e a do social. Este modelo é composto por práticas teóricas e intervenções que integram a saúde, o ambiente e a produção.

Defende que as sociedades humanas contemporâneas entendendo desenvolvimento como um processo dinâmico, com rupturas estruturais e reestruturações sucessivas, estão em princípio dispostas a aceitar que é legítimo reclamar um "desenvolvimento humano sustentável", buscando equacionar o equilíbrio entre saúde, ambiente e desenvolvimento, dentro de um processo democrático, com ampla participação social e de exercício da cidadania (Duval, 1998).

Realça que como método e prática para a produção de conhecimento e para a integração operativa na explicação e resolução dos cada vez mais complexos problemas de saúde, ambiente e desenvolvimento a interdisciplinaridade é requerida como conseqüência da necessidade de se estabelecer princípios epistemológicos e metodológicos para diferenciar e articular as relações natureza-sociedade.

No segundo texto dessa sessão, os coordenadores, conjuntamente assinam a elaboração da definição do conceito de Rede de Vigilância em Saúde, construindo uma tipologia de redes. E, justificam a construção desse modelo para articular institucionalmente às redes interativas diversificadas existentes a partir da mobilização dos diversos atores / agentes para tornar mais transparentes e eficazes os programas da esfera pública na saúde. 
Assumindo redes como conceito sociológico importante para se destacar a vida cotidiana como espaço estratégico para a articulação política e institucional das comunidades e grupos sociais, contra as tentativas dos modelos econômicos privatistas e individualistas de colonizar a vida cotidiana em detrimento do espaço público.

E, para compreender melhor essa mudança de perspectiva metodológica em favor das redes interativas produtoras de solidariedades, dádivas e reciprocidades ampliadas, ressaltam que é importante compreender a significação do "mundo da vida", expressão do filósofo alemão Jürgen Harbermas, que o sociólogo francês Alain Caillé denomina de "sociabilidades primárias". Esta expressão serve para designar aquela esfera de práticas sociais situadas fora do sistema formal - o mercado, o Estado e a Ciência, constituindo um fenômeno multidimensional e complexo.

Isto significa que cada sociedade possui lógicas particulares de organização institucional, existindo formas diversas de funcionamentos da realidade social que chamamos sociedade. Portanto, o uso teórico e metodológico do conceito de rede social na operacionalização da reforma na saúde, por exemplo, exige considerar que a Sociedade Civil constitui a base de um sistema autônomo - o da vida, o dos vínculos primários - que funciona por regras próprias diferentes daquelas presentes nos sistemas formais do Estado e do Mercado, que funcionam como aparelhos funcionais (Godbout, 2000).

Assume-se que no Social a lógica racionalista e tradicionalista dos aparelhos, diferentemente, não funciona eficazmente, e o que prevalece é a imprevisibilidade orgânica que gera instituições de formato horizontal e aberto a fluxos e refluxos inerentes aos sistemas complexos. Sendo a instituição típica do Social a rede interativa.

Por tudo isto as redes autoreguladoras de membros de família, amigos, vizinhos, constituem o único formato institucional adequados para a organização de modelos comunitários e associativos que são as bases do "sujeito de escolha" possível em cada sociedade, ou seja, o modo concreto da existência do sujeito histórico (Caillé, 2000). 
Estas informações são levadas em conta pelos autores para poder entender o mecanismo de "montagem" das Redes de Vigilância Sanitária. Estas redes atravessam os campos dos dois mundos - o da vida e o da esfera do poder e do dinheiro. E aí lançam como uma hipótese interessante, a de saber se é possível pensar na formação de uma Rede de Vigilância em que a presença da sociedade seja importante, provocando efeitos de redução da tendência de colonização do mundo da vida a partir de campos ancorados na racionalidade instrumental.

E, para eles, isto significa admitir que é possível um desenho organizacional de uma prática de política pública - controle sanitário - a partir de uma colaboração efetiva da sociedade civil nos campos propositivos e operacionais e também pensar uma densidade de capital social capaz de provocar processos organizativos na esfera da sociedade civil, contrabalançando os efeitos de dominação de uma prática de planejamento e intervenção tecnocrática autoritária.

Concluem que o conceito de rede social é estratégico para se pensar a formação de uma Rede de Vigilância em Saúde auxiliar do Sistema de Saúde, pois compartilha a idéia de que o social constitui um sistema que funciona a partir de regras próprias, as da dádiva, e que a vida comunitária e local não pode ser criada e administrada a partir de instâncias externas, sejam elas governamentais ou não.

Mas chamam a atenção para que, diferentemente da rede de movimentos, a Rede de Vigilância em Saúde apresenta como característica uma maior presença das instituições formais, sobretudo o Estado e a Ciência, devendo constituir na prática um sistema de ação mais formalizado que aqueles próprios da Sociedade Civil, mais marcadamente espontâneos.

Segundo os autores, por terem esta conformação, se constituem como um espaço intermediário entre Sociedade Civil, o Estado e a Ciência, essas Redes de Vigilância podem ser vistas como próprias de uma nova forma de organização da vida denominada de esfera cívica, um espaço híbrido e inédito, propiciado pela mundialização, que integra funções de aparelho s e de redes (Caillé, 2000).

E, para responder a um desafio de classificar os tipos de redes predominantes de modo a compreender o impacto organizacional e político dessas modalidades de práticas sociais, os autores elaboraram uma tipologia de redes que vão das redes sóciohumanas, como princípio orgânico de outras como a sócio-técnicas, que aparecem no plano das organizações formais, ou as sócio-institucionais que se reportam às parcerias entre agências de governamentais e não-governamentais. 
No terceiro texto, Breno Fontes assume a autoria da construção de um recorte teórico do fenômeno de estruturação de processos de sociabilidade a partir das trajetórias de formação de redes sociais e especificamente, propondo uma explicação de como as pessoas constroem círculos sociais, ilustrando o conceito de relés sociais com o exemplo das práticas profissionais dos agentes comunitários de saúde - ACS. Informa que este exemplo ilustrativo é fruto de uma pesquisa empírica, em andamento, sobre “Redes de Vigilância Sanitária".

Como fenômeno "relé social" é descrito como mecanismo que produz e divulga a mobilização dos indivíduos para novas redes, criando dessa forma "redes de redes", a partir de laços pré-existentes, novas pessoas são acessadas e nos insere em outras localizações institucionais no nosso espaço de sociabilidade.

Tomado de empréstimo a Ohlemacher (1999), o conceito de relé social introduz a idéia como instrumento para explicar processos de mobilização e recrutamento de militantes de movimentos sociais e é empregado como alternativa ao termo "broker", definido por Boissevain (1976) como "aquele que recodifica e seleciona um novo canal, codificando e transmitindo para o seguinte, ligando o ator em uma trilha de novas sociabilidades".

Definido como redes que funcionam como contexto para relações face a face apresentam como as seguintes funções dos relés sociais. Primeiro, funcionam como conexões entre redes não conectadas anteriormente ou "pontes" estabelecidas a partir de contatos sociais pré-existentes. Segundo formam o ambiente, a organização e a estrutura institucional de um grande número de relações face a face, através de círculos sociais que entrecruzam processos de sociabilidades imaginários de redes egoconcentradas. Terceiro, algumas redes (redes de mediação) geram novas redes (sub-redes) e ao mesmo tempo renovam o conteúdo das redes antigas (redes de procedência). Como quarta função é apresentada a mobilização de um relé social ultrapassar as suas próprias fronteiras.

Tomando como exemplo de construção de redes a prática profissional dos Agentes Comunitários de Saúde coloca como cenário a situação do Brasil que, a partir da Constituição de 1988, iniciou um processo de redirecionamento no planejamento das políticas públicas, com o desenho descentralizado das agências públicas e conseqüentemente com a valorização do local. 
Os governos federais e estaduais, antes os principais formuladores e executores das políticas, transferem parte importante das suas atribuições aos municípios. É neste contexto que se situa a Reforma Sanitária Brasileira e a implantação de um Sistema Único de Saúde - SUS.

O SUS surge como reflexo dessa concepção descentralizada e para o seu controle é introduzido mecanismo de participação popular, com a implantação dos Conselhos de Saúde, cuja composição incorpora representantes da sociedade civil, redistribuindo competências decisórias e aproximando essas agências das populações beneficiárias dos programas.

Por outro lado, inaugura-se também no país uma nova prática de atenção à saúde, com equipes de saúde da família e de saúde ambiental. Nesta, considera-se que o paciente inserido em um contexto familiar e comunitário, sendo enfatizada a importância do ambiente social na determinação do seu estado de saúde. Assim, a equipe de saúde age a partir do estabelecimento de "vínculos e da criação de laços de compromisso e de co-responsabilidade entre si e a população" (Scott, 2001).

O desenho da política do Programa de Saúde da Família (PSF) introduz na prática médica a variável "comunidade", a partir do núcleo familiar. As famílias, inicialmente objeto apenas da atenção do profissional médico, não são agora, simplesmente "tratadas" de suas doenças a partir do olhar clínico, uma atenção focada. À equipe tradicional (médico e enfermeiros) acrescenta-se o agente comunitário de saúde, novo personagem cuja principal característica é morar na comunidade e introduzir no cotidiano das famílias uma atenção a sua saúde.

Assim, pela própria forma de recrutamento - a exigência de morar na comunidade - o agente de saúde não se incorpora ã equipe de saúde sozinho, ele traz consigo as suas redes, as suas experiências de participação em grupos, associações, clubes, em fim a sua vida na comunidade (Brasil, 2002).

Para o contexto da cidade do Recife, capital do estado de Pernambuco no Nordeste do Brasil, cenário específico dessa observação, conta com 1800 ACS, atendendo a cerca de $70 \%$ da população, distribuídos em seis Distritos sanitários. Em cada Distrito Sanitário são colocadas diversas agências de atenção à saúde - os Centros de Saúde da Família onde se localizam as equipes de atendimento de saúde comunitária (Recife, 2002).

Para o Distrito Sanitário I, local onde foi realizada a pesquisa empírica tem uma população prevista para o ano de 2003 de 81.419 pessoas e, uma considerável 
concentração de bairros populares, uns com alta densidade demográfica e precária infra-estrutura urbana e outros com insignificante população residente pelo perfil comercial ou de serviços. Localiza-se em uma área central da cidade.

Trabalham neste Distrito 130 profissionais, dos quais 74 ACS. Na maioria, esses ACS, na sua maioria são mulheres e exercem a função, em média, há oito anos, têm idade média em torno de 35 anos e moram no bairro há mais de 20 anos. A maioria já completou o segundo grau e um número insignificante freqüenta ou freqüentou a Universidade.

O Trabalho do ACS é feito a partir de vistas as famílias e tem natureza fortemente pedagógica voltada para a educação em saúde bem como, encaminhar as pessoas para o Centro de Saúde e acompanhar o processo de tratamento, quando necessário.

É assinalado como fato importante o número expressivo de ACS que participam de associações de moradores. Quase a metade dos entrevistados participa de associações voluntárias, e de forma intensa - $42 \%$ são membros de diretorias ou participam de comissões. Embora não esteja previsto no organograma ou na rotina de trabalho do programa, as associações voluntárias são um importante aliado para o andamento do trabalho dessas Agentes.

Para o autor, pela própria natureza do trabalho, os ACS mantêm uma relação intensa com os diversos atores da comunidade, constituindo o que é designado acima de círculos sociais - especificamente, para este caso, padrões de sociabilidade atuando diretamente nos campos das práticas de saúde.

Conclui que ainda não ter informações suficientes para desenhar esses campos, nem para reconstruir as trajetórias dos atores sociais envolvidos mas, o que se pretende é com a idéia de relé social, traçar um quadro em que seja possível verificar o lugar dos ACS na construção desses círculos sociais e seu papel na intermediação entre o Setor Público e a comunidade.

O quarto texto, desta segunda sessão, é assumido pela Sanitarista Solange Laurentino e pela Epidemiologista Lia Giraldo Augusto, onde é exemplificado o novo desafio paradigmático a partir de uma situação concreta - uma pesquisa sobre a percepção da dengue pela população atingida.

Pretende-se nesta produção apresentar os pontos críticos identificados a partir de uma análise histórica e técnica dos programas instituídos pelo Ministério Nacional da Saúde. Foi verificado como se desenvolvem, no nível local, as ações orientadas pelo poder 
público e como a população percebe a doença e as condições sócio-ambientais que favorecem sua eclosão e manutenção.

Foi realizada uma pesquisa do tipo avaliativa aplicando a triangulação metodológica dos dados quantitativos e qualitativos, com o objetivo de estabelecer ligações de dados obtidos por diferentes fontes e reinterpretados à luz do marco teórico utilizado na sessão anterior.

Para isto, foi realizada uma extensa análise documental para quantificar e situar a morbidade focada bem como para compreender os fundamentos das estratégias de controle adotadas pelas instituições oficiais nos últimos anos. A partir desses dados foi reconstruída a história recente da Dengue, no mundo, no Brasil e em Pernambuco onde se localiza o município estudado e realizado as considerações críticas aos programas de controle adotados, no Brasil, nos últimos seis anos.

Também foram utilizadas como referencias as teorias das representações sociais como uma forma possível de se estudar o conhecimento do senso comum, considerando o sujeito como parte de um conjunto indissociável com o objeto e a sociedade. A partir desta perspectiva, buscou-se compreender os processos que ocorrem nos contextos socioculturais precisos (Santos, 1998) e para tanto foi realizada uma pesquisa com a população de Glória de Goitá, um pequeno município do estado de Pernambuco, com 27.554 habitantes. Foi, realizado, entrevista com questionário semi-estruturado.

Reconhece-se que a utilização de entrevistas individuais para captar a percepção sobre determinada problemática é um método limitado, mas justifica-se com a falta de tempo para a utilização de uma vivência, no local, como observador participante. Método que mais se aplicaria também pela limitação da percepção da população quanto à memória remota. Neste sentido, se buscou o desafio de aproximar os tempos, relacionando a informação atual com os dados registrados nos documentos.

Conclui-se que o modelo de Controle da Dengue desenvolvido no período de 1997 a 2000 não tem sido efetivo conforme o esperado, em virtude do planejamento ser vertical, paternalista, desconsiderar a percepção da comunidade sobre a doença e por não ser participativo; de não implementar ações de saneamento ambiental de caráter coletivo; de priorizar o uso de produtos químicos em detrimento das ações de manejo ambiental e de educação; de não se promover adequada assistência médica para confirmação dos casos e de melhoria no sistema de vigilância epidemiológica e por não considerar os contextos sociais e culturais em seu processo de comunicação. 
Para as autoras os programas de controle de vetores não internalizam o ambiente como parte do sistema de vigilância e sobre o qual deveriam agir para controlar os fatores de riscos gerados pelas forças motrizes e pelos contextos socioambientais desfavoráveis, e era essa a principal orientação que precisava ser introduzida na prática dos agentes de saúde no nível local.

Bem como, deveria ser estimulada a formação de Redes de Vigilância em Saúde que compartilhem a idéia de que o social constitui um sistema que funciona a partir de regras próprias, a da dádiva, porque a vida comunitária e local não pode ser criada e administrada a partir de instâncias externas, e que essas Redes podem ser um mecanismo eficaz para resgatar a visão complexa do processo saúde-doença própria da saúde coletiva (Martins, 2002).

A partir das críticas ao controle da dengue é sugerida uma nova abordagem com adoção de um modelo sustentável de controle da dengue, o que implicaria, principalmente, em uma nova consciência ecológica e sanitária da população, para que seja efetiva, sem criar novos riscos para a saúde e para o ambiente.

Assim, recomendamos esta obra por se constituir um esforço interinstitucional e interdisciplinar em vencer as barreiras das cátedras e caminhar na busca de uma transdiciplinaridade necessária para a abordagem dos campos da saúde coletiva e da sociologia como campos sociais e complexos, tanto para a sua compreensão como para as ações requeridas para uma intervenção.

\section{Bibliografia}

Brasil, Ministério da Saúde. Modalidade de contratação de Agentes Comunitários de saúde. Um pacto tripartite. Secretaria de Políticas de Saúde. Departamento de Atenção Básica, Brasília, MS.

Boissevain, J. (1976). Friends of friends. Networks, manipulators and coalitions. Oxford, Blackwell, p.152.

Caillé,A. (2000). "Entretien avec Alan Caillé: le paradoxe féconde du don" In: Pratiques. Les cahiers de la médicine utopique, décembre 1999/janvier 2000, n.8, Paris.

- (2002a). Antropologia do Dom: o terceiro paradigma. Petrópolis: Editora Vozes.

- (2002b). "Dádiva e associação" In: Martins,P.H.(org) A dádiva entre os modernos: discussão sobre os fundamentos e as regras do social. Petrópolis: Editora Vozes. 
Czeresnia, D. (2003). "O conceito de saúde e a diferença entre prevenção e promoção" In Czeresnia,D. e Freitas,C. (org). Promoção da saúde: conceitos, reflexões, tendências. Rio: Editora Fiocruz.

Durkheim, E.(1989). As formas elementares de vida religiosa. São Paulo: Editora Paulinas.

- (1997). Leçons de sociologie. Paris: Editora PUF.

- (1999). Da divisão do trabalho social. São Paulo: Editora Martins Fontes.

Duval, G.(1998). "Salud y ambiente en el proceso de desarrollo", Ciências \& Saúde Coletiva, 3(2): p. 7-32.

Elias, N. (1994). A sociedade dos indivíduos. Rio de Janeiro: Editora J orge Zahar.

Elias, N.; Scotson,J. (2000). Os estabelecidos e os outsiders. Rio de Janeiro: Editora Jorge Zahar.

Godbout,J.(1992). L'esprit du don. Paris: Ed. La Découverte.

- (2000). Le don, la dette et I'identité: homo donator vs homo economicus. Paris: La Découverte.

Kruze, B. (2001). “Introdução" In: A educação profissional em saúde e a realidade social; organizador: Kruze, B.). Recife, IMIPE: Ministério da saúde.

Martins, P.H.(2002). Contra a desumanização da medicina: crítica sociológica dos paradigmas médicos modernos. Petrópolis: Editora Vozes.

Martins, P.H. \& Fontes, B. (2004). Redes sociais e saúde: novas possibilidades teóricas. Recife: Editora Universitária da UFPE, 159 p.

Mauss, M.(2003a). "Esboço de uma teoria geral da magia", In: Sociologia e antropologia. São Paulo: Editora Cosac \& Naify.

- (2003b). "Ensaio sobre a dádiva: forma e razão da troca nas sociedades arcaicas" In: Sociologia e antropologia. São Paulo: Editora Cosac \& Naify.

Ohlemacher, T. (1999). "Brücken der mobilisierung. Soziale relais und persönliche netzwerke" e "Struktur und System. Eine Empiriebasierte Annäherung von Strukturaler Analyse und Systemtheorie In: Bürgerinitiativen gegen militärischen tie flug. habilitationsschrift na der Universität Hamburg.p.68 e ss.

Putnam, R. (1993). Making Democracy Work: Civic Traditions in Modern Italy. Princeton University Press.

Recife, Prefeitura da Cidade.(2002). (www.recife.pe.gov.br) link da Secretaria de Saúde. 
Santos, M. (1998). “O retorno do território" In: Santoas, M.; Souza, M.A.A.;Silveira, M.L. Território: globalização e fragmentação. São Paulo:HUCITEC, p.15-20.

Scott, P. (2001). Programas de Agentes Comunitários de Saúde da Família e dilemas de reprodução orientada. In: Gico, Vânia de Vasconcelos (et alli). As ciências Sócias - desafios do milênio. Natal, Ed. UFRN.p.889-905.

Tambelline, A.T. (2003). Notas introdutórias para pensar a questão das relações entre a saúde e o ambiente. Texto apresentado ao I Seminário de Saúde e Ambiente com Controle Social. Brasília: CNS. 